\title{
Discussion between David MacDougall and Gary Kildea about Doon School Chronicles
}

\section{Canberra, August-October 2002}

[Note: This discussion is edited from a longer conversation. Asterisks indicate where sections of the conversation have been omitted.]

G: Maybe you can talk a little bit about how you came to put Doon School Chronicles together like this...

D: The film changed quite radically during the process of making it, because initially I was attempting to look at the school as a kind of crossroads of people from different backgrounds. I had an idea of the school as a very heterogeneous place where there was a lot of mixing, and perhaps a lot of conflict. This was based on my preconceptions, and the fact that I was looking for some sort of cross-cultural engagement. But as I lived at the school for a while I began to feel that in fact it was a very homogeneous culture, a specially constructed kind of society with its own distinct boundaries.

There is an increasingly narrow focus as you move through the five Doon School films, from this film, Doon School Chronicles, ${ }^{1}$ which is about the whole school, to the next film, With Morning Hearts, ${ }^{2}$ which is about one group of first-year students. When you reach the fifth and final film, The Age of Reason, ${ }^{3}$ it's a portrait of one student. So I had an intention to move closer and closer. This first film therefore had to make the broadest kind of analysis of the school in terms of its ideology and history, but without losing sight of the experiences of people within it.

G: I think it's a very important part of your work, especially in this film, that you're very careful to quarantine your writing insights from your cinematic insights.

D: I wanted to establish some quite strict rules for looking at the film, communicated through the film's own structure. But I also wanted there to be other elements in the film that existed independently of the ideas that lay behind the structure, particularly in the way that the audience might engage

\footnotetext{
MacDougall, D. 2000, Doon School Chronicles, [140 mins] Ronin Films, Canberra.

MacDougall, D. 2001, With Morning Hearts, [110 mins] Ronin Films, Canberra.

MacDougall, D. 2004, The Age of Reason, [87 mins] Ronin Films, Canberra.
} 
with the place and the people. Even if they came away from the film with no specific conclusions, or only unconscious ones, they would still have had the satisfying experience of encountering people and places in a particular way.

In this I had a sense that rhythm and timing were important - the kind of timing that is created by a progression of shots. And little things, like the way in which a sound at the end of a scene will give you the point at which to cut to the next shot, because it's like a rhythmic foreshadowing of the cut. I've been conscious of that sort of quasi-musical structuring all the time in the editing.

G: The finished product of Doon School Chronicles looks so inevitable: it's so solid, so sure of itself in content and form...

D: I had no preconceptions about what sort of film it had to be. There was nobody looking over my shoulder saying you must bring us a ninety-minute documentary feature, or it must have a certain narrative structure, or a certain style to it. That was reassuring, because I was able to treat it more experimentally.

\section{View Opening Sequence of Doon School Chronicles ${ }^{4}$}

G: So we've just looked at the first six shots: the bicycle passing with some of the laundry on the ground; the woman shaking out the shirt; the women spreading the shorts on the ground; the shirts on the ground and the shorts hanging on the clothesline - six shots and the film's up and running. What can you say about it?

D: Why does the film begin this way? I suppose that is the main question. One part of the answer is that I wanted you to know you were in India. This is a problem posed at the beginning of any film. Where are we? Especially so if the title of the film doesn't give anything away. The title isn't Salaam India, for example. By showing these women, I felt the scene would tell you very quickly, very efficiently: 'This is India.' And then, of course, it would raise the question, 'What's going on here?' What is all this clothing that we see spread out? The scene moves from a general shot to closer shots of what are obviously uniforms. They are all blue, or blue and grey. We also move from the first shot, which is a wide shot of all the clothing - rather striking in itself, because there's so much of it - to the very abrupt sound of shaking out the clothing. This is a rhythmic element. It takes you by the scruff of the neck and says, 'Here we are. This is the sound of cloth.'

There's perhaps something very attractive in a simplification of life that involves everybody wearing the same clothes, but at the same time when you see clothing

4 View associated media files via the ANU E Press website at http://epress.anu.edu.au/titles/humanitiesresearch-journal-series/humanities-research-vol-xviii-no-1-2012 
hung up like that it's suggesting that the people are possibly interchangeable. This clothing would certainly be interchangeable if it didn't have the numbers sewn in for each boy. But the worry is that the people become interchangeable. So at the back of the film are my ambiguous feelings about this entire subject. And, of course, it's a central theme of the film: the contrast between order and individuality. It is built both emotionally and intellectually into the film.

G: We want to establish it's India, but you might also say, why didn't we start with a wide shot of the school, which we do have later, and that would establish that it's a school. What's withheld is as important...

D: Yes, exactly. It's trying not to tell you too much. If, for example, it were a shot that said 'School' — with buildings and students walking past them. The intention here was to withhold information about where we are, just giving you enough to make you wonder: 'What's going on here? Where are we? Why all this clothing?'

G: It says: bring your poetic sensibility to this. Be prepared to, not think, but feel-think; think and feel interpenetrated.

D: There's one other aspect to it too. I think the filmmaker has to impose his or her will on the audience from quite early in the film. You have to be saying: 'Well, either you're going to come with me on this journey or you're not.'

D: Under the image of a stack of shirts is a kind of bridge of sound. The sound of outdoor activity - of voices - comes up under it. And there's a still image. A number of the images here are stills. And for the first time you actually see a student.

G: And that's a purely formal image, more like a Mondrian painting.

D: Yes, and the way in which these blocks of colour appear on a school uniform are obviously part of the aesthetics of the school.

G: Yes, but also the aesthetics of David MacDougall.

D: Well, yes, it's a reinterpretation - and a heightening of the aesthetics. That's a question that comes up in relation to the film sometimes. People ask, 'To what extent are you revealing the school's own aesthetic system, and to what extent are you simply imposing your own aesthetic sense upon it - even aestheticising the school?' My response to that is that it's an interpretation of the school's aesthetics, through heightening, through exaggeration, through selection on my part. It's what I see and what I am trying to analyse. So that's the intellectual side of the equation. 
G: If you were just hand-holding, or even on a tripod, and even if the boy was perfectly still - the tiny, tiny pieces (even that goes for the shot with the clothing also in the linen room)-how would it be different if it was a tripod shot, say, of that clothing when nothing is moving, the camera's not moving, the clothes are not moving?

D: I don't know if it works this way for other people, but for me the very deadness of the still image acts as a kind of punctuation, and an invitation to move into the next part of the film. Which it does, because we go from the shot of the boy's back to the title card, which is about the backs and fronts of people - and the 'pack of cards' image, which I thought was a marvellous simile that the headmaster used. He was very fond of this sort of language, and it seemed very pertinent at this point in the film. The quotation - part of which is 'Now you can think of yourselves as a pack of cards, all with the same pattern of blue and grey on your backs' - ends up being about 'each boy's special character'. The shot that follows of the boys' faces during the call-over has a kind of 'Aha!' quality, because you say, 'Yes!' You should respond in that way, I think, as a viewer - in that 'Aha!' way. And then of course each boy is different. They have such different faces, represent such different cultures - there's a boy there from Sikkim - and they're all different sizes, even though they're the same age. So that becomes the bridge into the main title of the film.

D: The next section is the scene of measuring heights and weights that follows the main title. I see the idea of measurement as an important theme to announce just at this point - at the 'second beginning' of the film, so to speak. And of course it echoes the idea of uniforms - everything about that aspect of the school. And yet it's very lively and shows how these boys are boys like any others.

G: 'What is the measure of a man?' is the obvious thing that is suggested. Literally, what is the measure of an individual? And just as in the call-over, how does a system deal with a bunch of individuals? One is by naming them, giving them names, and calling them names, and making them own to the name. Another one is precisely to measure them.

D: Here I am also introducing the theme of adolescence and growth. The boys are being measured because they're growing up. You see them at different stages. The last boy is very small; the others are already practically men. And so, in a sense, we see that the film is also going to be addressing this period in people's lives when they are growing up, the transition from childhood to adulthood. 
Certainly filming measurement was something I wanted to do, but this scene so dominates everything with its own life, you know, that it overcomes anything that might be pinned on it as 'meaning'. Because these individuals on the screen are so oblivious of those meanings; it's partly that, isn't it?

G: In general terms, what a film like this is doing is harnessing the incredible power of the multiplicity of meanings that a film shot contains.

D: Then it shifts to introduce these boys in their room, and a very natural everyday scene of them eating biscuits.

G: So we've moved from the ultimate formality of the opening - the clothes on the ground, and also the human formality of the gentleman explaining to you exactly what each piece of clothing is, in a formal manner - through to the formality of the boys, where we get the idea planted, we're able to work on those ideas of the individual and names and measures and everything. And it suddenly says 'informality' and 'individual'. So it shows that we're moving somewhere.

D: The contrast is very important. In fact many films, but maybe especially this kind of film, work by constantly jumping ahead, forming juxtapositions between two scenes, so they reflect on each other in some way. You're propelled forward into a new place. And yet this transition also has a very nuts-and-bolts purpose, which is to introduce you to the characters, in the way that thousands of films do.

G: The first sound of the measuring, the man [measuring], and shunk! Then that measuring bar comes down on the guy's head with a sort of percussive sound. It's throughout the film, isn't it?

D: You can think of sounds as operating in all sorts of different ways. Sometimes they are integral to the shot; sometimes they are like punctuation, propelling you forward into the next scene or announcing something new in the scene. So in the editing one is very conscious of that kind of rhythmic progression, because it's often very necessary to carry the weight of materials that are not closely associated with each other and visually are quite complex. Yes, it's a way of carrying the audience forward.

D: I suppose what's most important for me in the scene of the classroom is the interaction that's going on among the students, and then between them and the teacher, and the boredom of classrooms that most of us remember, and the response to this boredom that they have. And of course, another thing that's very important in this scene is developing Rohan as a character - the small boy with glasses. 
G: In a way, it is the first scene where we're in classic observational cinema mode.

D: Although it is highly edited.

G: Oh yes, but that's not a contradiction.

D: But it's highly constructed, boiled down from a much longer observational scene.

G: Yes, but what I mean is [it's] the first time. Here the engagement for the first time is the pleasure of voyeuristically looking in on [the interaction in the classroom].

D: We now come to the segment with Rohan talking to the camera, followed by the shots leading into the assembly. Well, here it's of course going into a kind of interview mode, although I tried to keep it from being journalistic in style. And that was one reason for leaving the long opening where he says nothing and is simply thinking. Then the question comes. This is actually part of an hour-long interview with him. A lot of his importance in the film is, in a sense, retrospective. It's created after the fact in the editing, although I also filmed quite a lot about him in other situations. But the things he had to say were so interesting that he more or less worked his way into the film. The shots that follow quite intentionally pick up his idea of the artificiality of the school. He says, 'It was made artificial deliberately, I suppose.' And then you see the sculptures: artificial boys. And then a shot of the same sculptures but with live boys behind them. Then a fairly close shot of just legs and shorts as they're waiting, which is a reflection back on earlier scenes in the film.

G: This time it's the 'direct camera'. And I think it can't be called an interview. I think it can only be called a talk to camera, because an interview has its own fixed agenda, which it's trying to draw out. You get the feeling that it's really a discussion that has come to this. Remember the ideology of a certain form of cinéma-vérité where 'interviews', as they were called, were sort of forbidden and disallowed?

D: I can't think of many filmmakers who haven't used interviews of some kind at some point. There is such a range of possibility, all the way from the very formal interview to the kind of informal interaction you have with Celso in Celso and Cora, which is at the other end of the spectrum. ${ }^{5}$

G: In any kind of cinema, which is basically observational/participational, it would be very odd not to have discussions to camera. It would be very artificialor not so much artificial, but if you stuck to observation only, you're more or less

5 See the previous essay in this volume for Gary and David's detailed discussion of Celso and Cora. 
stuck with not acknowledging the camera's presence at all...Suddenly you get to observe in a different way. But it's very important that we know Rohan a bit already, before we get to talk to him.

D: Yes, that was important to establish beforehand. I thought it was crucial to bring him into the film before this scene. I know I selected him because of qualities that I admired in him. His articulateness, his ideas were important, not just because they advance the film but because they somehow establish him as a presence that makes the film worthwhile. The film is bearing witness to the existence of people like him.

G: So this little section takes us from the idea, which is Rohan speaking about the artificiality of the school, and the statues, the idea of artificiality. There's a little linkage, like so much of the film. In fact, it seems to me that almost every scene progresses to the next by some kind of linkage, whether it be of sound or idea or image.

D: This kind of linking is really a way of keeping the film together when the ingredients are otherwise so varied.

G: Yes, but it creates such a coherence that the film has the elegance and assurance of a good piece of writing, say - a piece of your own writing, for example.

D: I wouldn't draw a direct link between writing and film editing, but I know that in editing I'm often looking for these links. And since the film is not linked by chronology, it's a different way of organising things and directing attention to the way the ideas fit together, rather than events taking place chronologically, one after another. So I suppose if a film is in an essay form, rather than a strictly narrative form, there's some connection with writing.

If it has a sense of inevitability about it, of a written progression, that's of course only achieved through a lot of searching in the editing, a lot of trial and error in organising the material. This allows it to flow, both in terms of ideas and emotional content, and then of course in its pace, its rhythmic aspects, the alternation of different kinds of material that are nevertheless linked in some way. I think the reason this sort of film takes so much time to edit is because you don't have a clear and obvious framework, only a thematic and intellectual one. You don't have the framework of a central chronology.

When I'm filming I find that I'm constantly adding to a list of possible scenes that I might shoot. It's a rolling list. I'm adding new ideas every day to the bottom of the list - things I've seen or things I think might happen - and then as I go along I'm of course shooting some of those scenes and I'm able to cross them off the list. Or I may realise that something isn't really relevant to what I'm 
interested in, so I cross it off for that reason. It's a way of keeping ahead of me a set of possibilities that I can keep exploring, and thinking constantly about what the film needs.

G: Whereas another kind of filmmaking process might simply say, 'Oh, all we need is a line of commentary to make this clear'.

D: Yes. I'm always looking for the scene that will clarify something else I've shot, rather than an external structure that will explain it. But I suppose this comes out of an approach that's closer to the way that fiction films are constructed, because they explain themselves through a progression of scenes, not through an external commentary.

G: It's to some extent directed, because I think it's a combination of pushing a little bit and accepting to be pushed.

D: That's right. You have to be open to the unexpected. Because the situation itself is constantly teaching you new things, and if you went into the film with a script, knowing what you were going to say, then the filming process wouldn't be one of exploration. It would simply be a process of illustrating what you already knew at the start. And that's a totally different way of making films.

Of course, how you do it is not thought out at every moment. It's something that results from how you're resonating with that moment-where you place your body, where you aim the camera, how you frame things. All this is something that you learn through experience to do without thinking, and it's a very pleasurable process if things are going well.

The voice of the film changes register whenever it goes into the inter-titles. And yet because the inter-titles are all quotations, the register is not altogether different, because it is in a sense just another observation, in this case of writing. These quotations are fragments of writing that pertain to the school - that have been picked up, gathered, collected.

\section{ص View Dormitory Sequence of Doon School Chronicles ${ }^{6}$}

D: Then we go to [the] waking-up scene. Sound is very important throughout this section. It's about the sounds of early morning - and, later on, the sounds when they're doing their physical training. In the bathroom, too, sounds are very important. I think the whole mood of this is about early morning, and in a way all the things you hate to do in school: to get up in the morning, to wash,

\footnotetext{
6 View associated media files via the ANU E Press website at http://epress.anu.edu.au/titles/humanitiesresearch-journal-series/humanities-research-vol-xviii-no-1-2012
} 
the horrible exercises which, although everybody grumbles about them when they are in the school, they say years later they valued. Even the things they hated the most!

G: Everyone is in their own bed trying to face the idea of transiting from sleep mode to wake-up mode, which is always problematic.

D: It is a big shift from a public space to this personal space, which is very domestic, too-because we're now in a dormitory room. We can see also the very simple beds that they have, and the lack of possessions, and the rigour of this place. Although the school is a school of privilege, the living conditions are very simple, and that is all a part of the school's ideology.

G: And this is the first time we've felt a twinge of almost voyeuristic guilt that observational films often carry along with them. I think it's a very positive aspect of the film, because it gets us into another space. Do you feel that this is a sort of change of gear in the film?

D: Yes. It's true that it is an invasion of their sleep; for me, sleep is a sort of sacred condition. I am very hesitant ever to wake anybody up, because I almost feel that one doesn't have the right to. Here, clearly, I am there before they wake up, and one wonders, perhaps, 'How did he get there? Is he doing this without their permission? What right does he have to be there?' And so on. And then, of course, you recognise Rohan, I hope, whom we've met before, who's waking up, and who pulls the covers over his head. Audiences find that amusing because it's so expressive of not wanting to get up.

We've been in the room before, because we were there when they were having biscuits together, but that was a more cursory scene. This is now a bit deeper. Of course the truth of the matter is that I told them, 'Some morning you're going to find me here before you wake up'. They quite enjoyed the fact that they were going to be in the film - that I had selected their room and them-but when it came right down to waking up and finding a camera there, there's a bit of ambivalence in Rohan's expression.

G: It does sweep us up in precisely these observations of the rhythm of the morning and the attention to detail. We are out into the field suddenly with the exercises. We have the pleasure of a narrative of what happened next, and we have the pleasure of the rhythm, recognising the rhythm of life...The film is sort of tumbling along, despite it not having any real, sort of big narrative. It's tumbling along by this idea of contrast and development, and changing gear, changing register. And then when we get into Rohan's little character portraits, we have suddenly gone into a new register altogether, where we are now engaged at another level of audience interest. And that is the different characters, as seen through one of the characters. 
D: Then the film moves into the bathroom, which is more intimate still, because they're doing such things as combing their hair, going to the urinal, washing. And I think this maybe prepares you for the character sketches of them that come later, this inside view of Rohan and his friends.

G: Here are ideas about individuals - again coming back to the pack of cards. So not in an externally applied way, but in a very seemingly natural, integrated way. In Rohan telling about other characters, he is also telling us about his own character.

D: In this later scene in which Rohan describes his friends, I wanted the images to reflect the character of each boy. I think it's important that Rishabh is described as being both a bit clumsy and very intelligent, because one quality offsets the other. We have a sense that he isn't just clumsy, he isn't just naughty; he has another side - that he's very good at maths and physics and so on. And Rohan is willing to attribute this to him, to give him credit for it.

G: Yes, and the sophistication of his assessments is wonderful, and that's the true usefulness, the deepest meaning of the scene, I think. Simply the perspicacity of that boy, and that reminds us, as the rest of the film does, that young people are a lot smarter, a lot [more] complex and sophisticated than the adult world gives them credit for.

D: Yes, that's one of the objects of this whole project: to look at the rationality of childhood. Not just to look at childhood through the stereotypes of sentiment or immaturity or inadequacy, but to show that theirs is a coherent world.

\section{- View Arjun Sood Sequence of Doon School Chronicles ${ }^{7}$}

D: So now we're beginning a new chapter, a new part of the film: Chapter Six. And it's headed by a quintessential imperial statement about sport and character by A. E. Foot, the first headmaster, in 1938. 'By the age of fourteen, a Doon School boy should know the right way to hit, throw or kick any sort of ball at cricket, hockey, football or tennis. He should be able to bear the pain which is liable to be involved in most games without flinching.'

I suppose it's also convenient that they're playing cricket here, which is the quintessential imperial game. This section is now going to introduce us to a new character. In a way he is only the second character to be introduced, if we take Rohan's group of four in the dormitory as almost a single entity. This is Arjun Sood, a younger boy. He's in his second year, but he's clearly younger than

7 View associated media files via the ANU E Press website at http://epress.anu.edu.au/titles/humanitiesresearch-journal-series/humanities-research-vol-xviii-no-1-2012 
the others that we've been focusing on. What sort of character he is, and what sort of role he'll take in the film, still remains to be seen. But he's going to be a different sort of character.

Arjun gets in trouble finding the score cards and-I thought rather surprisingly and quite winningly — he asks for help, which is something I don't think would happen in our culture. He just quite easily says: I'm in trouble; help me. And the other boy runs to his assistance and helps him and they get it right.

G: It's the sort of ironic sense of the whole film's perspective that the real, the far more interesting drama is happening keeping the score, keeping the scoreboard going than actually making the runs...

D: Yes, we only see a very brief shot of the cricket match. It's all going on at the periphery. As a footnote to this, I should tell you that I shot this scene with a little one-chip camera, a Sony PC 7, that I'd taken with me on my first visit to the school, when I stayed there only about two weeks. I was using it as a kind of note-taking device. I was just learning to use it and feeling my way into events that were going on around the school. And I was meeting people. One of the people I met was Arjun. So this scene turned out to be useful later on when he became more prominent as a character in the film.

G: The boxing scene is contrastive and full of action. What can you say about the whole boxing scene?

D: It's mindful of movies and boxing on television. It's constructed around those tropes about boxing. It's also very condensed and impressionistic, in the sense that the three rounds are shortened-particularly the second round in which only three punches are thrown, I think. All the focus is on the sidelines. And the scene fits within the context of A. E. Foot's nostrum about bearing the pain of games without flinching. It's a scene about the production of masculinity and manhood in a school like this, within the cultural context that created it historically.

I needed to let the scene settle down before going on to the scene of Arjun's retrospective view of it, which in fact wasn't the next day but some months later. You can tell that he's a bit older looking, he's grown a bit. Another theme of this part of the film, of course, is growth: physical growth and the transformation from being a child to being a man. And that sort of biological growth underpins the cultural expectations about childhood and manhood that I mentioned before: the construction or making of men, which is one reason for the later montage of images of Arjun at progressively older ages. It's an attempt to nail down that theme. 
That shifts into a discussion of his weight and his height, and he makes the very open remark, 'Yes, this is the time that you grow, twelve or thirteen'. I like it when he says he's thirteen, and then adds, 'and a half'. Because at this age a half-year is like a decade; it's a huge transformation. Then we go to the montage of images of him. The first one is from the early scene when he was keeping the scoreboard for the cricket match. Those that follow were shot at roughly sixmonth intervals, as he grew older.

G: So for you, those stills are really saying this is growth; it's continuing the theme of that conversation precisely about growth and change.

D: Many documentary filmmakers have recourse to interviews because they do give you access to aspects of life that might be more difficult to film as actually lived. But in this project I tried to impose on myself the discipline of using interview material only to a limited extent, and to make the film speak in other ways, even though the interview material is quite important.

G: I think it's appropriate if the film includes some conversation to camera because, again, it's more or less analogous to how we go about in the world and how we get to know people, and a place, and situations - a bit by conversation, but, more perhaps than anything else, by observation. So this reflects the kind of mix that we have when we go about in the world, about how we become familiar with something - a situation or people.

D: There are some stills here. They are very composed, almost reminiscent of a certain style of photography before the Second World War - spoons in close-up, for example. I still find things are very beautiful when looked at in that way.

G: And it is like taking us by the scruff of the eyeballs, as it were, and forcing us to break out of the temporal sometimes - to segue, again, into that photographer's sensibility - alertness to the joy to be had in the sheer look of things, and then the sound of things, and the rhythm of things. It's a well-placed sequence, in keeping with the others, which of course couldn't have worked at all if it was the only one in the film. To me, it's just a reprise of that part of the film's concern with the physical world.

G: The scene with Rohan is quite restful in its own way - extremely laidback conversation where he's very much at ease, and he's very much at ease in taking his time to formulate an answer. That characterises his little answer to your question about what's the nature of intelligence.

D: I gave him as much time as possible at the head of the shot before I asked the question, just to let things settle and establish a feeling of quietness. And the question about intelligence is of course a tough question to ask anybody. But I put it experimentally, to see how he would respond, and I was amazed by the 
intelligence of his answer-his very calm and articulate way of saying, 'I think intelligence is a degree of perfection with which you reply, with which you react to situations'. In a way, he leads us into the next section, since the shot ends with him asserting that intelligence is how you react to situations. Then we enter just such a scene, which is cued by that.

One point about this conversation with Rohan is that I didn't have a precise list of questions, although I obviously had certain things I wanted to ask him about. But the idea of asking him about intelligence at that moment just came to me. I felt he was ready for it at that psychological moment. He would be able to deal with that kind of question. And it was a mark of my esteem for him that I could put such a very adult question to him, because I felt he would say something that wouldn't simply be an automatic response.

G: Yes, and a very important part of the scene is that he reflects that, and you can see that he appreciates being treated as a sort of equal.

G: What's striking about this scene [with Veer], or this departure for the film at this point, is that it seems to go against common accepted wisdom-ninety minutes in, almost - to introduce a new character. How do you feel structurally about that?

D: It's true that Veer enters very far along in the film, but it reflects my view, I suppose, that a film can be novelistic rather than modelled on the theatre or the short story. It can have the kind of evolution in which an important new character enters quite late. And it actually picks up the film. It projects it forward into a new zone. In a film this long, that's maybe even necessary. It's not only the introduction of a new character; the film enters a new style of filmmaking in several ways. The first way is in the very intimate direct-tocamera moment when he's asking about the technicalities of the camera. But the scene as it progresses is also quite different from any of the previous sections. It becomes a little story, a film within a film, a play within the play.

G: You say it's more novel-like, but probably there are only a few novels which also would start introducing a character three-quarters of the way through.

D: I felt that by dividing the film up into ten chapters I had a certain freedom to make each of them different in a way-you know, to make each of them distinctive. I wasn't bound to preserve the same style throughout; in fact, the very opposite. Each chapter deserved a different treatment, a different approach. So the ten chapters taken together would form a multi-perspectival and multivocal study of the school. 
D: The story that now unfolds is about the making of a film by Veer. It's also an exploration of his character. The way he took charge in this scene surprised me. He had an almost authoritarian approach in that meeting. He controlled the discussion.

G: Yes, this becomes very much a cinéma-vérité kind of portrait of personality and power and those kinds of things. It's slightly less formalistic than earlier parts of the film. Perhaps because we're with the older boys, we're suddenly alert to the social interaction. It's not novel in the film, but there does seem to be a slight movement towards it, a slight shift, do you think?

D: Yes, it's more of a 'direct cinema', or cinéma-vérité scene. It's a condensation of the meeting, but I think it's very observational in the sense that you mean. Also, depending on your point of view, it's cut rather crudely or abstractly. I'm not trying to preserve a sense of continuity so much as trying to go to the heart of the meeting. And I really had no choice but to cut it abruptly, and even make something of a feature of that in the editing. It cuts to Veer a number of times out of continuity, so that it's clear that it's a time-cut in each case.

Later we go to the close-ups of shoes and boys trying to clean them off with bits of paper and leaves. It's amusing and it picks up on some of the earlier shots in the film about shoes and feet, which seem to be important in the school and which express, at least to me, something about the character of the boys. And if you can hear it, they're talking about a prefect who catches everybody, even if there's only a little dust on their shoes. It finishes with the joke of one boy polishing his shoe on another boy's stocking.

G: Yes, that's a perfect little [instance], the fruit of observation. It's comic and revealing.

D: Audiences always respond to that moment because it's so quirky. But I think it shows the kind of cooperation that the boys have against authority. There's a feeling that they accept this because they've all got to avoid being punished for having dirty shoes. Later, the scene of the 'change-in-break' punishment brings together a lot of the same elements: clothing, power, the seniors' power over younger students. The sequence is actually made up of material shot at two quite different times. One of the older boys, who's been signing chits, explains the process, because I asked him to. It's a case of the filmmaker directly asking for an explanation, for information. So he tells how it works. What's nice about it, from my point of view, is that the process is still going on around him.

G: Yes, it's fantastic. Deep in the shot, the boy is approaching - the subject of what we're being told about - that is, the boy under punishment. He approaches from the distance and comes right up, and it's a perfect mis en scène. 
D: Scenes should always have more than one reason for being - and, if possible, two or three. Just as when you write a sentence, it should have more to it than just its denotative meaning.

G: This scene of regimentation is more potent than other scenes of regimentation in the film - the marching. This seemed to be almost more joyous than, say, the other marching, which looked more militaristic.

D: Maybe it's the feeling of impulsive forces at work underneath.

G: Elemental forces of fire and destruction.

D: At the very end of the scene the boys go wild and go running off-after having performed in even rows. There's a kind of rush offstage that has a certain wildness about it. Somewhere in the background there may be a connection with the scene earlier in the film when Rohan speaks of a mob being uncontrollableeven if you don't consciously make that connection.

G: Yes, definitely. And again that comes back to the theme of the whole film and this tension between order and the chaos of the mob-or even the chaos of individual desire against society's imperatives.

D: I liked coming back to Rohan asleep after the torchlight tattoo, because it seems like another world altogether. It's very quiet. It gives a sense of the next day: the quietness, the relaxation after a big event, when people are getting back to their ordinary lives.

G: And the final scene - the lights-out scene - works very nicely. Again, it gets us back to the 'little things'. Filmmaking is about the 'little things' - about time and space.

D: For me, it has a special feeling, with the mosquito nets. The light is even different. It's as if they've made this their home, and it's a home they're going to have to leave sometime.

G: I think your film has the sense that you're quite willing in your filmmaking to give up a lot of - virtually all-direct explanation. And your representation is by carefully, elegantly placed, 'found' pieces, which end up making sense. But it's that modest epistemology which ends up paying off handsomely, precisely because you're not fighting against the medium. And I think it's what your whole career has been seeking to discover: what's the way to maximise this medium? Didn't we mention before our old friend Bresson's aphorism 'It is in its pure form that art hits hard'? I think this film hits hard in that way. 
Humanities Research Vol XVIII. No.1. 2012

D: Well, that's probably a good note to end on. One could do worse than end with Bresson. ${ }^{8}$

G: Couldn't do better.

D: Couldn't do better either.

8 Bresson, R. 1977, Notes on Cinematography, Urizon Books, New York. 